\title{
Cognitive deficits in post-stroke aphasia
}

\section{Déficits cognitivos na afasia pós-AVE}

\author{
Milena V. Bonini1,2, Márcia Radanovic ${ }^{1}$
}

\begin{abstract}
The assessment of aphasics' cognitive performance is challenging and such patients are generally excluded from studies that describe cognitive deficits after stroke. We evaluated aphasics' performance in cognitive tasks compared to non-aphasic subjects. A sample of 47 patients (21 aphasics, 17 non-aphasics with left hemisphere lesions and 9 non-aphasics with right hemisphere lesions) performed cognitive tasks (attention, verbal and visual memory, executive functions, visuospatial skills and praxis). Aphasic patients performed poorer than all non-aphasics in Digit Span $(p<0.001)$, Clock-Drawing Test $(p=0.006)$, Verbal memory $(p=0.002)$, Visual Memory $(p<0.01)$, Verbal Fluency $(p<0.001)$, and Gesture Praxis $(p<0.001)$. Aphasia severity correlated with performance in Trail Making test part B ( $p=0.004)$, Digit Span forward ( $p<0.001)$ and backwards $(p=0.011)$, and Gesture Praxis $(p=0.002)$. Aphasia is accompanied by deficits not always easy to be evaluated by cognitive tests due to speech production and motor impairments. Assessment of cognitive functions in aphasics might contribute to optimize therapeutic intervention.
\end{abstract}

Keywords: aphasia, stroke, memory, executive function, attention, cognition.

\section{RESUMO}

A avaliação cognitiva de afásicos é difícil e tais pacientes são frequentemente excluídos dos estudos que descrevem déficits cognitivos pós-AVC. Avaliamos o desempenho de afásicos em tarefas cognitivas comparados a não-afásicos. Um grupo de 47 indivíduos (21 afásicos, 17 não-afásicos com lesão à E e 9 não-afásicos com lesão à D) realizou testes cognitivos (atenção, memória verbal e visual, funções executivas, habilidades visoespaciais e praxias). Afásicos apresentaram pior desempenho do que não-afásicos em Extensão de Dígitos $(p<0,001)$, Desenho do Relógio $(p=0,006)$, Memória Verbal $(p=0,002)$, Memória Visual $(p<0,01)$, Fluência Verbal ( $p<0,001)$ e Praxias Gestuais ( $p<0,001)$. A gravidade da afasia correlacionou-se com o desempenho no Teste de Trilhas parte B ( $p=0,004)$, Extensão de Dígitos direta $(p<0,001)$ e inversa $(p=0,01)$, e Praxias Gestuais $(p=0,002)$. Afasia é acompanhada por déficits difíceis de ser avaliados devido às deficiências de expressão e motoras. A avaliação das funções cognitivas em afásicos pode otimizar a intervenção terapêutica.

Palavras-chave: afasia, acidente vascular cerebral, memória, função executiva, atenção, cognição.

Approximately one third of patients who survive the first weeks after stroke are aphasic. Aphasia due to stroke is associated with increased mortality, worse functional recovery, and lower chances of returning to work activities ${ }^{1}$.

Language processing depends on other cognitive functions such as attention, memory, executive functions and visuospatial abilities, which act as supportive systems. On the other hand, much of human`s thinking pattern rely on language itself, which renders it to be a critical function in reasoning, abstract thinking, and problem solving. It is well established that language and other cognitive functions are interrelated, and researchers' efforts are currently focused on searching for evidence on how and to what degree the different cognitive domains are recruited to interact with each other, as well as on the impact of a particular cognitive function impairment in other functions². One factor that permeates this interrelation between cognitive functions is the overlap of anatomical sites affected in vascular lesions, because the same brain region can be simultaneously required to participate in different cognitive functions ${ }^{3}$.

Most neuropsychological tests used to assess aphasics' performance in non-linguistic tasks depend on verbal expression, and therefore, have proven to be unsuitable, especially in severe aphasia ${ }^{4}$.

In recent years, the concept of vascular cognitive impairment has gained much attention in the literature, as it proposes a new framework for establishing the relationship between cerebrovascular disease and cognitive decline, which encompasses a spectrum varying from various forms of vascular mild cognitive impairment (VaMCI) to vascular dementia (VD). Aphasia may hamper an accurate appraisal of general cognitive abilities due to the difficulties in performing

\footnotetext{
1 Universidade de São Paulo, Faculdade de Medicina, Departamento de Neurologia, Sao Paulo SP, Brazil;

${ }^{2}$ Universidade de São Paulo, Hospital Universitário, Sao Paulo SP, Brazil.

Correspondence: Marcia Radanovic; Rua Cristiano Viana, 163/ap.92;05411-000 São Paulo SP, Brasil; E-mail: marciaradanovic@yahoo.com.br Conflict of interest: There is no conflict of interest to declare.

Received 04 February 2015; Received in final form 20 May 2015; Accepted 08 June 2015.
} 
a reliable neuropsychological evaluation in this population. This, in turn, may lead to misclassification of patients as possible VaMCI / VD instead of probable VaMCI / VD if there is not documented evidence of normal cognitive function prior to the onset of aphasia ${ }^{5}$. In fact, there is a tendency toward excluding aphasic patients in studies addressing cognitive outcome in stroke patients ${ }^{6}$.

The heterogeneity of response in patients with the same degree of aphasia under similar therapeutic interventions has raised the question about the role of other cognitive functions in this variability. Nicholas ${ }^{7}$ have found poorer performance when training alternative communication in aphasics who presented executive dysfunction, and Fillingham et al. ${ }^{8}$ reported that episodic and working memory, as well as reasoning impairments affected aphasics' performance during anomia therapy. These studies point to the importance of the assessment of cognitive functions in aphasic patients in order to optimize the therapeutic efforts.

Although the notion that aphasia constitutes a major obstacle to an adequate neuropsychological evaluation is considered "common sense", very few studies addressed this issue objectively in order to investigate which abilities are more compromised and to quantify this impairment. A survey on PuBMed database using the terms: "aphasia" and "neuropsychological assessment" returned 61 papers (back to 1977), only one addressing cognitive evaluation of aphasic patients; "aphasia" and "neuropsychological tests" returned 1844 papers (back to 1975), only 21 addressing the subject; "aphasia" and "cognition" or "cognitive assessment" returned 1617 papers (back to 1949), only 17 addressing the subject; finally, "aphasia" and "cognitive tests" returned 752 papers (back to 1967), only 12 addressing the subject. After excluding papers in duplicate, we reached the total number of 33 studies addressing cognitive functions in aphasia due to stroke in a period of over 60 years. Also, to the best of our knowledge, there are not similar studies conducted in Brazil. Data driven from these studies display a very heterogeneous profile in performance for aphasics; this is due mainly to methodological bias, as the criteria for patients' enrollment have dramatically changed over decades, as a result of advances in neuroimaging diagnosis. But, in general, aphasic patients tend to perform poorly in attention, executive functions, working memory and verbal memory tasks, with a great deal of dispersion that can be attributed to type and severity of aphasia ${ }^{9}$.

Considering the difficulties in the cognitive evaluation of aphasic patients and the clinical implications for diagnosis and rehabilitation, a better understanding of the cognitive profile of aphasic patients is warranted.

The present study aimed to: a) evaluate the performance of aphasic patients in cognitive tasks (attention, verbal memory, non-verbal memory, executive functions, visuospatial skills); b) compare the performance of aphasic and non-aphasic stroke patients in the mentioned tasks; and c) correlate the performance of aphasic patients in cognitive tasks with aphasia severity and time elapsed from stroke.

\section{METHOD}

\section{Participants}

Forty-seven individuals over 18 years old, with diagnosis of first stroke episode confirmed by CT brain scan were enrolled in the study. Patients were recruited from an outpatient service at a university hospital, as part of the "Stroke Morbidity and Mortality Study" (EMMA - Estudo da Morbidade e Mortalidade do Acidente Vascular Encefálico), a epidemiological surveillance study of cerebrovascular disease in progress at the institution. The minimum time interval between stroke occurrence and enrollment in the study was two months.

Individuals who presented previous strokes, previous or current history of drug abuse (including alcohol), current use of drugs affecting the Central Nervous System in doses that could impair cognitive performance, previous history of neurological and / or psychiatric disorders that could hamper cognitive performance or communication (such as epilepsy, schizophrenia, depression, severe brain trauma, dementia), and non-correctible visual / auditory deficits that could interfere with the evaluation were excluded from the study. From an original cohort of 466 patients, only 47 fully satisfied all the inclusion criteria. The main causes for non-enrollment were: previous stroke (130 patients), stroke not confirmed by neuroimaging (85), death (83), and schooling below 2 years (45). All patients signed a consent form prior to the enrollment in the study. The study was approved by the ethics committee of the institution where it was performed.

\section{Materials and procedures}

Participants underwent the following battery of tests and questionnaires: Boston Diagnostic Aphasia Examination $(\mathrm{BDAE})^{10}$, Gesture Praxis Protocol (BDAE) ${ }^{10}$, Trail Making Test (TMT A and B) ${ }^{11}$, Visual Cancellation Test ${ }^{3}$, Word List Memory, Word List Recall, Word List Recognition, Praxis and Constructional Praxis Recall (CERAD) ${ }^{12}$, Digit Span (forward and backwards) ${ }^{13}$, Visual Memory (BCB-Edu) ${ }^{14}$, the Clock-Drawing Test $(\mathrm{CDT})^{15}$, and FAS-COWA. Depressive symptoms were evaluated through the Hamilton Rating Depression Scale 21-item version (HRDS-21) ${ }^{16}$, with a cut off score of 7. Handedness was evaluated through the Edinburgh Inventory ${ }^{17}$. Quality of life of aphasic subjects was assessed by the Stroke and Aphasia Quality of Life Scale-39 (SAQOL-39), a scale that measures the perception of quality of life in four domains: Physical, Psychosocial, Communication, and Energy ${ }^{18}$. Our selection of tests was based on the Cognitive Linguistic Quick Test (CLQT), a battery developed by Helm-Estabrooks (not available in Brazilian Portuguese) to evaluate cognitive functions in neurological patients, including those with 
communication disorders ${ }^{19}$. We sought for tests that are well known in the literature, as well as those for which normative data in the Brazilian population is available.

According to the results obtained in the BDAE and BNT (see Appendix 1), participants were classified as aphasics $(n=21)$ and non-aphasics $(n=26)$. The distribution of patients according to aphasia type was as follows: global aphasia $(n=5)$; Broca 's aphasia $(n=3)$; transcortical motor aphasia $(n=1)$; Wernicke's aphasia $(n=3)$; transcortical sensory aphasia $(\mathrm{n}=3)$; conduction aphasia $(\mathrm{n}=1)$; anomic aphasia $(\mathrm{n}=2)$; mixed transcortical aphasia $(\mathrm{n}=3)$.

Patients were examined by a speech therapist with expertise in Neurolinguistics. Evaluation sessions lasted two hours, in average. More than one session was scheduled when the participant demonstrated or reported fatigue, so we were able to obtain the subject's best performance.

To compare the performance on cognitive tests, our sample was divided into three groups: aphasics $(n=21)$, non-aphasics with left hemisphere (LH) lesion (NAph $\mathrm{L}, \mathrm{n}=17$ ) and non-aphasic with right hemisphere $(\mathrm{RH})$ lesion (NAph $\mathrm{R}, \mathrm{n}=9$ ). This comparison aimed to estimate the effect of the lesion side and of the presence of aphasia in the participants' performance.

Continuous variables (which presented a non-gaussian distribution) were compared among the three groups by the non-parametric Kruskall-Wallis test, and multiple comparisons were carried out when appropriate, using the Dunn's post-hoc test. To compare the frequency of distribution of categorical variables, we used the Fisher's Exact Test and Chi-square test for independent samples.
Spearman's correlation was employed to verify the relation between severity of aphasia and time elapsed from stroke onset and the performance of aphasics in all non-linguistic cognitive tasks. Aphasia severity was measured using the Aphasia Severity Scale, from the BDAE, with a score varying from 0 to 5 (the higher the score, the milder the aphasia). The statistical analysis was performed using the software MedCalc ${ }^{\circ}$ for Windows version 10.0. A significance level (p) of 0.05 was adopted for all tests.

\section{RESULTS}

The groups were matched by age, education and time between the stroke and evaluation, and the homogeneity of the sample is presented in Table 1 . There was a statistically significant difference between groups in the HRSD-21, with a higher frequency of depressive symptoms among aphasics. The most common neurological impairment was hemiparesis (observed in $76 \%$ of aphasics, $53 \%$ of non-aphasics with $\mathrm{LH}$ lesion, and $33 \%$ of non-aphasics with $\mathrm{RH}$ lesions) followed by hypoesthesia (observed in $52 \%$ of aphasics, $18 \%$ of non-aphasics with LH lesion, and $33 \%$ of non-aphasics with $\mathrm{RH}$ lesions). A description of lesion sites for aphasics and non-aphasics is provided in Appendix 2.

Aphasics had poorer performance than non-aphasics in the Digit Span (forward and backwards), Word List Memory, Visual Memory, Constructional Praxis Recall, CDT, FAS-COWA), and Gesture Praxis. There were not

Table 1. Sample characterization according to demographic and clinical data.

\begin{tabular}{|c|c|c|c|c|c|}
\hline Variable M (SD) Range & Aphasic $(n=21)$ & NAph L $(n=17)$ & NAph R $(n=9)$ & $\mathrm{p}$ & Multiple comparison $(p<0.05)$ \\
\hline Age (ys.) & $59.2(12.5) 31-82$ & 62.7 (13) $32-80$ & $59.5(12.6) 35-78$ & 0.114 & NA \\
\hline Schooling (ys.) & $7(3.8) 4-15$ & $6.0(3.6) 2-13$ & $8.2(4.5) 4-17$ & 0.337 & NA \\
\hline Time from onset (mo.) & $17.9(13.3) 2-45$ & $16.2(8.2) 2-34$ & $14.5(10.4) 2-33$ & 0.762 & NA \\
\hline HRSD - 21 & $5.8(2.4) 2-13$ & $4.3(2.4) 1-9$ & $3.2(1.4) 1-5$ & 0.012 & Aph $\neq$ NAph $L \& R$ \\
\hline SAQOL-39 & $3(0.8) 1.2-4.4$ & $3.9(0.5) 2.9-4.8$ & $4.3(0.4)$ & $<0.001$ & All groups differ \\
\hline \multicolumn{6}{|l|}{$\mathrm{Sex}^{\star}$} \\
\hline Male & 6 & 10 & 5 & 0.134 & NA \\
\hline Female & 15 & 7 & 4 & & \\
\hline \multicolumn{6}{|l|}{ Handedness** } \\
\hline Right & 21 & 15 & 0 & 0.376 & NA \\
\hline Ambidextrous & 0 & 2 & 0 & & \\
\hline \multicolumn{6}{|l|}{ Stroke type** } \\
\hline Ischemic & 21 & 15 & 7 & 0.113 & NA \\
\hline Hemorrhagic & 0 & 2 & 2 & & \\
\hline \multicolumn{6}{|c|}{ Neurological symptoms** } \\
\hline Hemiparesis & 16 & 9 & 3 & 0.071 & NA \\
\hline Hypoesthesia & 11 & 3 & 2 & 0.056 & NA \\
\hline Hemianopia & 2 & 3 & 1 & 0.746 & NA \\
\hline Dysarthria & 0 & 2 & 1 & 0.273 & NA \\
\hline Dysphagia & 3 & 1 & 0 & 0.389 & NA \\
\hline Dysphonia & 2 & 3 & 2 & 0.618 & NA \\
\hline
\end{tabular}


significant differences in the performance of aphasic and non-aphasic patients in the Visual Cancellation Test and in the TMT (A and B), although there was a trend for a worse performance of LH damaged and aphasic patients. In the Word Recognition task, LH damaged (both aphasic and non-aphasic) performed poorer than RH damaged patients (Table 2).

Aphasia severity correlated with scores in the TMT part B $(\mathrm{r}=-0.917, \mathrm{p}=0.004)$, Digit Span forward $(\mathrm{r}=0.860, \mathrm{p}<0.001)$ and backwards $(r=0.543, p=0.01)$, and Gesture Praxis $(r=0.668, p=0.002)$. Time elapsed from stroke onset did not correlate with any measures of cognitive function.

\section{DISCUSSION}

Impairment in cognitive tasks in aphasic patients has been systematically described in the literature for decades ${ }^{20}$. In 2002, Helm-Estabrooks ${ }^{9}$ systematized the approach to cognitive deficits in aphasic patients, proposing a new instrument to assess five main domains in this population. Ever since, most papers have put in evidence the interrelation between language and attention, executive functions, memory, and visuospatial skills as a two-way street where language is affected by impairment in any other function and vice-versa. Such approach aims to provide optimization of rehabilitation efforts, which must consider the global cognitive status of the patient. Seniów et al. ${ }^{21}$ described visuospatial memory and abstract thinking deficits in aphasics, with great heterogeneity in performance.

In the TMT, assessing selective attention, speed of perceptual processing and mental flexibility, performance was found to be below normal for all groups, especially in Part B. Only seven aphasics were able to perform the test; fourteen patients had impeding right hemiparesis. Therefore, our results are not to be considered representative of cognitive impairment per se in the aphasic group, and this test may be considered as a non-suitable method for evaluating LH damaged and aphasic patients.

Aphasic patients performed poorer than non-aphasic in the Digit Span test (both forward and backwards), which assesses attention, working memory, and mental control. Although this task requires verbal output, there was no time limit to perform it; even in these conditions, aphasic patients displayed a much worse performance. De Renzi and Nichelle ${ }^{22}$ described the same finding, which is now thought to reflect a deficit in the phonological loop (the verbal component of working memory ${ }^{23}$.

Table 2. Performance of Aphasics and non-Aphasics in cognitive tasks.

\begin{tabular}{|c|c|c|c|c|c|}
\hline Task M (SD) Range & Aphasic $(\mathrm{N}=21)$ & NAph $L(N=17)$ & NAph $\mathrm{R}(\mathrm{N}=9)$ & $\mathrm{p}$-value & Multiple comparison $(p<0.05)$ \\
\hline FAS-COWA & $3.2(4.5) 0-16$ & $20.3(8.9) 6-40$ & $27.1(7.7) 17-41$ & $<0.001$ & All groups differ \\
\hline Visual Cancellation test & $2.2(2.7) 0-11$ & $1.6(1.4) 0-5$ & $0.9(0.8) 0-2$ & 0.439 & NA \\
\hline \multicolumn{6}{|l|}{ Trail Making } \\
\hline Part A (sec) & $155.9(113.5) 56-401$ & $144.9(131.2) 39-526$ & $97.3(22.8) 68-144$ & 0.457 & NA \\
\hline Part B (sec) & 291.6 (126.6) $150-479$ & $241.8(143.2) 74-560$ & $280.2(90.6) 163-408$ & 0.268 & NA \\
\hline \multicolumn{6}{|l|}{ Digit span } \\
\hline Forward & $2.6(2.2) 0-6$ & $8.3(1.7) 6-12$ & $8.4(1.3) 7-10$ & $<0.001$ & Aph $\neq$ NAph L \& R \\
\hline Backwards & $0.6(1) 0-3$ & $3.6(1.9) 2-10$ & $4.1(1.3) 2-6$ & $<0.001$ & Aph $\neq$ NAph L \& R \\
\hline \multicolumn{6}{|l|}{ CERAD } \\
\hline \multicolumn{6}{|l|}{ Word list memory } \\
\hline Trial 1 & $2.3(2.4) 0-8$ & $3.8(1.8) 0-8$ & $3.8(1.4) 1-6$ & 0.059 & NA \\
\hline Trial 2 & $3.3(3.1) 0-10$ & $5.8(1.7) 3-8$ & $6.3(1) 5-8$ & 0.007 & Aph $\neq$ NAph L \& R \\
\hline Trial 3 & $3(3) 0-9$ & $6.7(1.6) 3-9$ & $7.8(1.4) 6-10$ & $<0.001$ & Aph $\neq$ NAph L \& R \\
\hline Total & $8.6(8.3) 0-27$ & $16.3(4) 9-22$ & $17.9(2.9) 12-23$ & 0.002 & Aph $\neq$ NAph L \& R \\
\hline Word list recall & $2.4(2.9) 0-10$ & $5.1(2.4) 2-10$ & $6.1(1.2) 4-8$ & $<0.001$ & Aph $\neq$ NAph L \& R \\
\hline Word list recognition & $7.3(3.4) 0-10$ & $8.3(1.7) 5-10$ & $9.9(0.3) 9-10$ & 0.017 & Aph \& NAph $L \neq$ NAph R \\
\hline Constructional praxis & $5.9(2.7) 0-10$ & $7.7(2.1) 4-10$ & $7.3(1.7) 5-10$ & 0.092 & NA \\
\hline Recall of constructional praxis & $3.9(3.1) 0-10$ & $6.7(2.7) 2-10$ & $6.3(2.4) 3-10$ & 0.016 & Aph $\neq$ NAph L \& R \\
\hline \multicolumn{6}{|l|}{ Visual memory (BBRC-Edu) } \\
\hline Naming & $8.5(2.9) 0-10$ & $10(0) 10-10$ & $10(0) 10-10$ & 0.001 & Aph $\neq$ NAph L \& R \\
\hline Incidental memory & $3.7(2.7) 0-9$ & $5.2(1.6) 2-8$ & $5.6(1.4) 4-8$ & 0.075 & NA \\
\hline Immediate memory 1 & $4.8(3.4) 0-10$ & $7.4(1.7) 5-10$ & $8.3(1) 7-10$ & 0.006 & Aph $\neq$ NAph L \& R \\
\hline Immediate memory 2 & $5(3.5) 0-10$ & $8.3(1.5) 6-10$ & $8.9(0.9) 7-10$ & 0.001 & Aph $\neq$ NAph L \& R \\
\hline Delayed recall & $4(3.8) 0-10$ & $7.4(1.9) 4-10$ & $8.4(1.2) 7-10$ & 0.004 & Aph $\neq$ NAph L \& R \\
\hline Recognition & $9.2(2.2) 0-10$ & $10(0) 10-10$ & $9.5(1.3) 6-10$ & 0.103 & NA \\
\hline CDT & 5.5 (3) $0-9$ & $7.9(2) 2-10$ & $8.2(0.8) 7-9$ & 0.006 & Aph $\neq$ NAph L \& R \\
\hline Gesture Praxis & $34.5(16.5) 2-57$ & $58.2(2.4) 50-60$ & 59 (1.6) $23-24$ & $<0.001$ & Aph $\neq$ NAph L \& R \\
\hline
\end{tabular}


Attention has been extensively studied in aphasic patients in the recent years, as attentional deficits may impair auditory comprehension (i.e., comprehension of single words) as well as sentence comprehension and production ${ }^{4,24}$.

Most previous studies tended to focus on a specific attention ability (i.e., sustained, selective, divided attention, and so on) or modality (auditory, visual), and therefore results tend to be quite inconsistent. Korda and Douglas ${ }^{25}$ compared aphasics' and normal subjects' performance in a sustained attention task reporting only an increasing in reaction time for both groups. Helm-Estabrooks ${ }^{9}$ found preserved visual discrimination and attention in a group of aphasics. Kalbe et al. ${ }^{4}$ reported that aphasic patients performed poorly in at least one of the three cognitive functions assessed in their study (memory, attention and reasoning). Murray $^{2}$ also reported attentional deficits in aphasic patients, and correlated those deficits with language and other cognitive functions, with implications for rehabilitation strategies. Hinckley et al. ${ }^{26}$ described impairment of attention in aphasic patients, including poor performance in the Visual Cancellation Test. We found a trend to a poorer performance of patients with $\mathrm{LH}$ damage in this task, more pronounced in the aphasic group. However, attention is a complex function encompassing several abilities, and the relations between distinct attention functions and language are yet to be understood.

Verbal fluency tasks demand intact executive functioning as well as semantic storage. As would be expected, aphasic patients performed poorer in phonological fluency as a result of difficulties in speech initiation and production, and semantic impoverishment. Impairment in the lexical-semantic processing in the LH lesions is well described, but there is evidence of impairment in this process also in $\mathrm{RH}$ lesions ${ }^{27}$.

In the Constructional Praxis task, all groups presented poor performance, but there was no disadvantage for the aphasic group. Only the CDT (which poses greater executive demand) differentiated aphasics from non-aphasics. Helm-Estabrooks ${ }^{9}$ found greater difficulty of aphasic subjects in performing the tasks proposed in the CLQT ${ }^{19}$, which increased proportionally to executive functioning demands. The author concludes that executive functions are the second most affected cognitive abilities in brain damage associated with aphasia (aside from language itself). Hinckley et al. ${ }^{26}$, seeking for evidence about executive functions interference in aphasia therapy, described a delay of aphasics to fulfill the criteria to initiate formal language therapy.

In the Word List memory task, which assesses verbal memory, aphasics had a performance below normal in immediate and delayed recall tasks, while NAph L and NAph R groups showed normal performance. De Renzi and Nichelli ${ }^{22}$ reported LH damaged patients to perform poorer in short-term memory tasks (verbal and non-verbal), with aphasic patients exhibiting greater impairment than non-aphasics. Verbal memory impairment in aphasics is currently considered to be due to phonological loop deficit, which hampers the ability to retrieve verbal encoded material ${ }^{23}$. However, aphasic patients showed improvement of performance in the word recognition task when compared to spontaneous recall, which shows a relatively preserved capacity of encoding information, suggesting also the interference of organizational spontaneous searching strategies difficulties.

In the Visual Memory task, aphasics performed poorer than non-aphasics in all subtasks, except for recognition, a finding previously published ${ }^{28}$. The improved performance in the Recognition task suggests a relative preservation of nonverbal encoding with deficit in retrieval strategies, similar to that observed for verbal stimuli. Verbal encoding is used for storing visual as well as verbal information, and subvocal rehearsal is one of the mechanisms by which material stored in the visuospatial sketch gains access to the phonological output buffer ${ }^{23}$.

Regarding Gesture Praxis, ideomotor apraxia, speech apraxia, and orofacial apraxia are well known to frequently occur in association with aphasia. In our sample, there was improvement in aphasics' performance on imitation for natural gestures, conventional gestures, use of functional objects, and orofacial praxis (raw data not shown). This improvement occurred in $78 \%, 68 \%, 65 \%$, and $50 \%$ of aphasic patients, respectively for each of the aforementioned task, and it might be related to the presence of dissociative apraxia, in which the conceptual system for action (the stored knowledge of actions) and the action production system (sensorimotor programmes) are preserved, but cannot be accessed by verbal command ${ }^{29}$.

Aphasics show great heterogeneity in performance on cognitive tasks ${ }^{9}$. The interference of hemiparesis and the difficulties of verbal production are factors that pose an additional burden in this group of patients. In tasks with greater motor requirements, such as the TMT, which depends on motor speed is an additional obstacle to these patients. The same holds true for tasks relying mostly on verbal output.

The linguistic-cognitive interrelation is evidenced by the correlations found between severity of aphasia (which is related to lesion $\operatorname{siz}^{30}$ ) and the subjects' performance in the TMT (Part B), Digit Span, and Gesture Praxis Test, where the performance was inversely proportional to the severity of aphasia; there is a large overlapping of fronto-parietal networks for language, attentional-executive, praxis, and motor functions) rather than for memory or visuospatial tasks (in which there is participation of mesial temporal and right hemisphere structures). This methodological difficulty is unlikely to be overcome in clinical studies as strokes are distributed according to the vascular anatomy and not according to the underlying cognitive circuits. Studies enrolling a greater number of cases, which allow the comparison of groups according to more specific and isolated cerebral lesions (e.g. frontal, parietal) are warranted and might contribute to the understanding of the co-dependence between language and other cognitive functions. Likewise, the comparison of groups according to the type of aphasia would allow a better 
understanding of the impact that specific changes in verbal production and comprehension exert on the performance of aphasic subjects.

Limitations of our study are the small number of subjects in the sample, the heterogeneity of vascular lesions and clinical types of aphasia, as well as the need for verbal response in most non-linguistic cognitive tests. Right hemiparesis may also account for the poorer performance of aphasic patients, although it is true only for those tasks that require drawing (e.g., Visual Cancellation Test, TMT A and B, Constructional Praxis, and CDT).

One of the challenges faced by clinicians and rehabilitation professionals working with aphasics is how to perform a reliable cognitive assessment to identify which functions are preserved and which are impaired. Such knowledge can directly influence the choice of the most appropriate therapeutic intervention for each patient. For this reason, specific batteries have been developed in order to assess cognitive functions in aphasic patients, such as the $C L Q T^{18}$, and the Aphasia Check List $(A C L)^{2}$, the latter designed for patients with severe aphasia. However, these batteries are not yet regularly used in the assessment of Brazilian Portuguese speakers. The lack of appropriate instruments to evaluate aphasics can lead them to be regarded as VCI or even VD, and vice-versa, as many clinicians tend to be overly lenient and never submit these patients to a thorough cognitive evaluation due to their language impairment.

In conclusion, our study contributes to the understanding of Brazilian aphasics' pattern of performance in cognitive functions. Moreover, this study reinforces the need to develop and/or validate specific instruments for the assessment of cognitive abilities in aphasic subjects in Brazil.

Appendix 1. Performance of Aphasics and Non-aphasics in the BDAE, BNT and verbal fluency tests,

\begin{tabular}{|c|c|c|c|c|c|}
\hline Task M (SD) Range & Aphasic $(\mathrm{N}=21)$ & N Aph L $(\mathrm{N}=17)$ & N Aph R $(\mathrm{N}=9)$ & $p$-value & Multiple comparison $(p<0.05)$ \\
\hline \multicolumn{6}{|l|}{ Conversation and Narrative } \\
\hline Simple social questions & $3(2.6) 0-7$ & $6.9(0.24) 6-7$ & $7(0) 7-7$ & $<0.001$ & Aph $\neq$ NAph L \& R \\
\hline Spontaneous speech & $1.5(1.3) 0-3$ & $5(0) 5-5$ & $5(0) 5-5$ & $<0.001$ & Aph $\neq$ NAph L \& R \\
\hline Cookie Theft Picture & $1.5(1.4) 0-4$ & $4.6(0.5) 4-5$ & $4.9(0.3) 4-5$ & $<0.001$ & Aph $\neq$ NAph L \& R \\
\hline \multicolumn{6}{|l|}{ Oral Comprehension } \\
\hline Word discrimination & $11.4(4.3) 1-16$ & $14.9(1) 13-16$ & $15.1(0.7) 14-16$ & 0.002 & Aph $\neq$ NAph L \& R \\
\hline Commands & $5(2.9) 0-9$ & $9.6(0.6) 8-10$ & $9.5(0.5) 9-10$ & $<0.001$ & Aph $\neq$ NAph L \& R \\
\hline Complex ideational material & $2.2(1.9) 0-5$ & $4.8(0.6) 4-6$ & $5.1(0.6) 4-6$ & $<0.001$ & Aph $\neq$ NAph L \& R \\
\hline \multicolumn{6}{|l|}{ Oral Expression } \\
\hline Automatized sequences & $2(1.5) 0-4$ & $4(0) 4-4$ & $4(0) 4-4$ & $<0.001$ & Aph $\neq$ NAph L \& R \\
\hline Word repetition & $2.7(2.2) 0-5$ & $5(0) 5-5$ & $5(0) 5-5$ & 0.001 & Aph $\neq$ NAph L \& R \\
\hline Phrase repetition & $0.7(0.9) 0-2$ & $2(0) 2-2$ & $2(0) 2-2$ & $<0.001$ & Aph $\neq$ NAph L \& R \\
\hline Responsive naming & $3.7(4.1) 0-10$ & $9.8(0.3) 9-10$ & $9.8(0,4) 9-10$ & $<0.001$ & Aph $\neq$ NAph L \& R \\
\hline Category specific naming & $5.7(5.3) 0-12$ & $11.9(0.2) 11-12$ & $11.9(0.3) 11-12$ & $<0.001$ & Aph $\neq$ NAph L \& R \\
\hline \multicolumn{6}{|l|}{ Reading } \\
\hline Letter-word matching & $2.9(1.5) 0-4$ & $4(0) 4-4$ & $4(0) 4-4$ & $<0.001$ & Aph $\neq$ NAph L \& R \\
\hline Number matching & $3.2(1.2) 0-4$ & $3.8(0.3) 3-4$ & $4(0) 4-4$ & 0.027 & Aph $\neq$ NAph L \& R \\
\hline Word-picture matching & $2.7(1.1) 0-4$ & $3.8(0.3) 3-4$ & $3.9(0.3) 3-4$ & $<0.001$ & Aph $\neq$ NAph L \& R \\
\hline Word reading & $6.8(6.4) 0-15$ & $14.6(1) 11-15$ & $15(0) 15-15$ & $<0.001$ & Aph $\neq$ NAph L \& R \\
\hline Sentence reading & $1.2(1.8) 0-5$ & $4.2(1.5) 1-5$ & $5(0) 5-5$ & $<0.001$ & Aph $\neq$ NAph L \& R \\
\hline Sentence comprehension & $0.9(0.9) 0-3$ & $2.3(0.9) 0-3$ & $2.9(0.3) 2-3$ & $<0.001$ & Aph $\neq$ NAph L \& R \\
\hline Reading comprehension & $1.5(1.1) 0$ - 3 & $3.2(0.7) 1-4$ & $3.2(0.4) 3-4$ & $<0.001$ & Aph $\neq$ NAph L \& R \\
\hline \multicolumn{6}{|l|}{ Writing } \\
\hline Letter form & $6.5(5.3) 0-14$ & $11.7(2.7) 7-14$ & $13.7(0.4) 13-14$ & 0.001 & Aph $\neq$ NAph L \& R \\
\hline Letter choice & $9.3(7.4) 0-21$ & $19.3(2.6) 12-21$ & $20.6(0.7) 19-21$ & $<0.001$ & Aph $\neq$ NAph L \& R \\
\hline Motor ability & $5.6(4.7) 0-14$ & $11.2(3.1) 7-14$ & $13.2(1.6) 9-14$ & 0.001 & Aph $\neq$ NAph L \& R \\
\hline Coding skills & $2.8(3.2) 0-9$ & $7.9(1.9) 2-9$ & $8.5(0.5) 8-9$ & $<0.001$ & Aph $\neq$ NAph L \& R \\
\hline Written confrontation naming & $1(1.3) 0-4$ & $3.1(1.3) 0-4$ & $4(0) 4-4$ & $<0.001$ & Aph $\neq$ NAph L \& R \\
\hline \multicolumn{6}{|l|}{ Narrative writing } \\
\hline Writing mechanics & $0.6(0.8) 0-2$ & $1.3(0.4) 1-2$ & $1.8(0.5) 1-2$ & 0.001 & Aph $\neq$ NAph L \& R \\
\hline Vocabulary access & $0.4(0.6) 0-2$ & $2(0.9) 0-3$ & $2.3(0.8) 1-3$ & $<0.001$ & Aph $\neq$ NAph L \& R \\
\hline Syntax & $0.4(0.6) 0-2$ & $1.9(0.8) 0-3$ & $2.3(0.5) 2-3$ & $<0.001$ & Aph $\neq$ NAph L \& R \\
\hline Content adequacy & $0.3(0.5) 0-2$ & $2(0.8) 0-3$ & $2.5(1) 0-3$ & $<0.001$ & Aph $\neq$ NAph L \& R \\
\hline Total Writing & $1.7(2.3) 0-8$ & $7.2(2.7) 1-11$ & $8.9(2.3) 4-11$ & $<0.001$ & Aph $\neq$ NAph L \& R \\
\hline BNT & $17.5(16.8) 0-45$ & $46.2(8.5) 33-58$ & $48.9(5.9) 40-59$ & $<0.001$ & Aph $\neq$ NAph L \& R \\
\hline Animal fluency & $3(3.2) 0-10$ & $12.5(3.2) 6-19$ & $13.4(3.2) 8-19$ & $<0.001$ & Aph $\neq$ NAph L \& R \\
\hline
\end{tabular}

NAph L: non Aphasic left hemisphere lesion; NAph R: non Aphasic right hemisphere lesion; BNT: Boston Naming Test. 
Appendix 2. Cerebral lesion sites for Aphasic and Non-aphasic groups.

\begin{tabular}{lcc}
\hline Lesion site & Aphasic $(\mathrm{n}=21)$ & Non-aphasic $(\mathrm{n}=26)$ \\
\hline Left & 21 & 16 \\
Frontal & 1 & 1 \\
Parietal & 5 & 2 \\
Temporal & 1 & - \\
Occipital & - & 1 \\
Fronto-parietal & 3 & 3 \\
Temporo-parietal & 4 & - \\
Temporo-occipital & - & 1 \\
Parieto-occipital & - & 1 \\
Fronto-temporo-parietal & 5 & - \\
PVWM & - & 1 \\
Basal ganglia & 2 & 1 \\
Thalamus & - & 5 \\
Right & 0 & 9 \\
Frontal & - & 1 \\
Occipital & - & 1 \\
Fronto-temporal & - & 1 \\
Fronto-parietal & - & 2 \\
Fronto-temporo-parietal & - & 1 \\
Basal ganglia & - & 2
\end{tabular}

\section{References}

1. Laska AC, Hellblom A, Murray V, Kahan T, Von Arbin M. Aphasia in acute stroke and relation to outcome. J Intern Med. 2001;249(5):413-22. doi:10.1046/j.1365-2796.2001.00812.x

2. Murray, LL. Attention and other cognitive deficits in aphasia: presence and relation to language and communication measures Am J Speech Lang Pathol, 2012;21:S51-64. doi:10.1044/1058-0360(2012/11-0067)

3. Mesulam, MM, editor. Principles of behavioral and cognitive neurology. 2nd ed. New York: Oxford University Press; 2000. Chapter n०1, Behavioral neuroanatomy, p. 1-120.

4. Kalbe E, Reinhold N, Brand M, Markowitsch HJ, Kessler J. A new test battery to assess aphasic disturbances and associated cognitive dysfunctions - German normative data on the aphasia check list. J Clin Exp Neuropsychol. 2005;27(7):779-94. doi:10.1080/13803390490918273

5. Gorelick PB, Scuteri A, Black SE, Decarli C, Greenberg SM, ladecola $C$ et al. Vascular contributions to cognitive impairment and dementia: a statement for healthcare professionals from the American Heart Association/American Stroke Association. Stroke. 2011;42(9):2672-713. doi:10.1161/STR.0b013e3182299496

6. Sachdev PS, Brodaty H, Valenzuela MJ, Lorentz L, Looi JC, Wen $W$ et al. The neuropsychological profile of vascular cognitive impairment in stroke and TIA patients. Neurology. 2004;62(6):912-9. doi:10.1212/01.WNL.0000115108.65264.4B

7. Nicholas M, Sinotte MP, Helm-Estabrooks N. Using a computer to communicate: Effect of executive function impairments in people with severe aphasia. Aphasiology, 2005;19 (10/11), 1052:65.

8. Fillingham JK, Sage K, Lambon Ralph MA. The treatment of anomia using errorless learning. Neuropsychol Rehabil. 2006;16(2):129-54. doi:10.1080/09602010443000254

9. Helm-Estabrooks N. Cognition and aphasia: a discussion and a study. J Commun Disord. 2002;35(2):171-86. doi:10.1016/S0021-9924(02)00063-1

10. Goodglass H, Kaplan E, Barresi B. The Boston diagnostic aphasia examination. 2nd ed. Philadelphia: Lippincot Williams Wilkins; 2001.
11. Reitan RM. Validity of the Trail Making Test as an indicator of organic brain damage. Percept Mot Skills.1958;8(3):271-6. doi:10.2466/pms.1958.8.3.271

12. Morris JC, Heyman A, Mohs RC, Hughes JP, Belle G, Fillenbaum $G$ et al. The Consortium to Establish a Registry for Alzheimer's Disease (CERAD). Part I. Clinical and neuropsychological assessment of Alzheimer's disease. Neurology. 1989;39(9):1159-65. doi:10.1212/WNL.39.9.1159

13. Wechsler D. Wechsler memory scale-revised manual. San Antonio: The Psychological Corporation; 1987.

14. Nitrini R, Caramelli P, Porto CS, Charchat-Fichman H, Formigoni AP, Carthery-Goulart MT et al. Brief cognitive battery in the diagnosis of mild Alzheimer's disease in subjects with medium and high levels of education. Dement Neuropsychol. 2007;1(1):32-6.

15. Sunderland T, Hill JL, Mellow AM, Lawlor BA, Gundersheimer J, Newhouse PA et al. Clock drawing in Alzheimer's disease: a novel measure of dementia severity. J Am Geriatr Soc. 1989;37(8):725-29. doi:10.1111/j.1532-5415.1989.tb02233.x

16. Hamilton M. Rating depressive patients. J Clin Psychiatry. 1980;41(12 Pt 2):21-4

17. Oldfield RC. The assessment and analysis of handedness: the Edinburgh inventory. Neuropsychology. 1971;9(1):97-113. doi:10.1016/0028-3932(71)90067-4

18. Hilari K, Byng S, Lamping DL, Smith SC. Stroke and Aphasia Quality of Life Scale-39 (SAQOL-39): evaluation of acceptability, reliability, and validity. Stroke. 2003;3498):1944-50. doi:10.1161/01.STR.0000081987.46660.ED

19. Helm-Estabrooks N. Cognitive linguistic quick test. San Antonio: The Psychological Corporation; 2001.

20. Beeson PM, Bayles KA, Rubens AB, Kaszniak AW. Memory impairment and executive control in individuals with stroke-induced aphasia. Brain Lang. 1993;45(2):253-75. doi:10.1006/brln.1993.1045

21. Seniów J, Litwin M, Leśniak M. The relationship between non-linguistic cognitive deficits and language recovery in patients with aphasia. J Neurol Sci. 2009;283(1-2):91-4. doi:10.1016/j.jns.2009.02.315 
22. De Renzi E, Nichelli P. Verbal and non-verbal short-term memory impairment following hemispheric damage. Cortex. 1975;11(4):341-54. doi:10.1016/S0010-9452(75)80026-8

23. Baddeley A. Working memory and language: an overview. J Commun Disord. 2003;36(3):189-208. doi:10.1016/S0021-9924(03)00019-4

24. Kemper S, Schmalzried R, Herman R, Mohankumar D. The effects of varying task priorities on language production by young and older adults. Exp Aging Res. 2011;37(2):198-219. doi:10.1080/0361073X.2011.554513

25. Korda RJ, Douglas JM. Attention deficits in stroke patients with aphasia.J Clin Exp Neuropsychol. 1997;19(4):525-42. doi:10.1080/01688639708403742

26. Hincley JJ, Carr TH, Patterson JP. Relationship between cognitive abilities, treatment type, and treatment time in aphasia. Paper presented at the 31st Annual Clinical Aphasiology Conference; 2001 May 29-June 2; Santa Fe, NM. (Aphasiology. 2002;16(4-6).

27. Joanette Y,Ansaldo Al, Kahlaoui K, Côté H, Abusamra V, Ferreres A et al. [The impact of lesions in the right hemisphere on linguistic skills: theoretical and clinical perspectives]. Rev Neurol. 2008;46(8):481-8. Spanish.

28. Gainotti G, Cappa A, Perri R, Silveri MC. Disorders of verbal and pictorial memory in right and left brain-damaged patients. Int J Neurosci. 1994;78(1-2):9-20. doi:10.3109/00207459408986041

29. Greene JD. Apraxia, agnosias, and higher visual function abnormalities. J Neurol Neurosurg Psychiatry. 2005;76(Suppl 5):v25-34. doi:10.1136/jnnp.2005.081885

30. Forkel SJ, Thiebaut de Schotten M, Dell'Acqua F, Kalra L, Murphy DG, Williams SC et al. Anatomical predictors of aphasia recovery : a tractography study of bilateral perisylvian language networks. Brain. 2014;137(7):2027-39. doi:10.1093/brain/awu113 